\title{
A intervenção do serviço social ao paciente renal crônico e sua família
}

Social service intervention

with chronic insufficiency renal patient and his family

Grizy Augusta Centenaro ${ }^{1}$

Abstract This article has the objective to share the experience of professional performance of the Social Assistant in health, more precisely with carriers of chronic insufficiency renal, who need treatment of hemodialyses, reporting the limitations imposed for the illness and the confrontation of the patient and his/her relatives.

Key words Social service, Chronic renal illness, Family, Guarantee of rights
Resumo Este artigo tem como objetivo compartilhar a experiência de atuação profissional do assistente social na saúde, mais precisamente com pacientes portadores de insuficiência renal crônica, que necessitam de tratamento de hemodiálise, relatando as limitações impostas pela doença e o enfrentamento do paciente e seus familiares. Palavras-chave Serviço social, D oença renal crônica, Família, Garantia de direitos 
Introdução

0 relato da experiência que apresentamos acontece na Clínica Renal Oeste, no município de Chapecó, SantaCatarina, queteveinício das suas atividades em 1987. Contudo, as atividades do serviço social somente tiveram início em 1998, a partir da Portaria $n^{\circ} 2.062$, decretada pelo $M$ inistério da Saúde, a qual exige o profissional assistente social em clínicas de diálise.

Trabalhar com pacientes renais crônicos terminais incide em lidar com a dor, sofrimento e perdas constantes; portanto, pensamos a prática social deforma interdisciplinar, que vem apre sentando-se como uma possibilidade de garantir uma qualidade de vida para essas pessoas.

A concepção dequeo processo saúdee doença ultrapassa 0 aspecto biológico e envolve todo o contexto social, político e cultural do indivíduo, incluindo sua família, acompanha-nos desde o período de graduação na universidade, de forma que, quando tivemos oportunidade em nossa atuação profissional enquanto assistente social de conviver com portadores de doença renal crônica (IRC), submetidos ao tratamento de hemodiálise, passamos a perceber de forma mais clara os aspectos importantes das condições de vida dessa população, cuja doença éincurável eo tratamento, doloroso e causador de muitas limitações e alterações de grande impacto, tanto na sua vida como de seus familiares.

A família precisa se reorganizar etambém se adaptar, pois o paciente necessita de cuidados. Os papéis e funções devem ser repensados e distribuídos de forma que se auxilie o paciente na elaboração de sentimentos confusos e dolorosos, provocados pelo processo do adoecer.

$\mathrm{N}$ a maioria das vezes, a rotina do paciente se restringe a consultas médicas, sessões de hemodiálise três vezes por semana por um período de quatro horas a sessão, estando o paciente restrito a uma dieta e principalmente limitado à execução de tarefas que requeiram esforços físicos, pois sente-se muito fraco e cansado. M uitos que são chefes de família e donas de casa se submetem a algumas atividades artesanais para manter o sustento da casa e da família.

Após iniciarem o tratamento, a vida social dos pacientes se altera de tal forma que ficam impedidos de viajar devido ao tratamento, deixam de visitar amigos e vizinhos, sentem-se inválidos e muitas vezes sem assunto, a não ser falar de sua própria doença.

$\mathrm{N}$ a realidade, as pessoas submetidas à hemodiálise preocupam-se com problemas muito reais, geralmente sua condição clínica éimprevisível e sentem muitas reações adversas ao tratamento e às medicações; a maioria apresenta depressão por viver como um doente crônico e ter medo de morrer.

Com esteartigo, pretendemos descrever nossa experiência profissional e algumas repercussões psicossociais causadas pela doença crônica na família.

Acreditamos que a atuação do serviço social junto ao paciente em tratamento de hemodiálise seconstitui no acompanhamento do pacienteno sentido de enfrentar a doença e orientar o paciente e a família sobre todo o processo de tratamento e, principalmente, na garantia de direitos.

\section{Discussão}

O trabalho do serviço social na saúde, especificamente no atendimento ao paciente portador da doença renal crônica terminal, visa cada vez mais dar assistência integral ao paciente, aprimorando as técnicas e processos de trabalho, fundamentais para mediar os conflitos do paciente e sua família.

Quando uma pessoa possui uma doença incurável, que requer tratamento de longa duração eque impõelimitações, provoca muitas alterações de grande impacto, que repercutem na vida do paciente. Por isso, é necessário estarmos atentos na abordagem ao paciente è família, de maneira a evitar equívocos em seu tratamento, a adequada seleção de estratégias para obter 0 comportamento desejado e a adequação da informação à capacidade de compreensão do doente. Tais fatores podem auxiliar a adesão do paciente ao tratamento, pois temos que levar em consideração que a cultura é um fator que também pode influenciar na adesão ao tratamento, já que a compreensão é baseada em seu próprio sistema de crenças.

0 doutor me disse: "Você tem um problema renal, terá quefazer hemodiáli ise". Dejeito nenhum, nunca hemodiálise eu não faço, antes disso eu me mato. Eu não faço. $\mathrm{Na}$ hora me deu um choque, né! U m desespero. Eu pensei, hemodiálise, puxa vida, eu vou morrer. Então eu morro antes. Quando me disseram que eu ia fazer hemodiálise, eu achei que ia morrer. [Paciente aposentado]

A fala desse paciente exemplifica a reação do abalo psicológico mencionado por Lima et al. diante da notícia de uma doença crônica: Quando o diagnóstico é realizado e posta a situação de cronicidade [segundo momento], a reação geral é 
um sentimento de caos, de impotência. A família sente-seconfusa, conturbada. U m terceiro momento surge. Esse marcado por reações no que concerneà gravidade da doença eà sua irreversibilidade. Enfim, quando a invalidez, seja ela mínima ou grave, éadmitida, podesobreviver uma depressão apoiada simultaneamente numa agressividade intensa ou em reações de luto ${ }^{1}$.

A experiência como profissionais atuantes ao cliente renal no contexto da hemodiálise nos permite perceber que não só o paciente é abalado pela doença, mas também toda sua rede de relações, principalmenteo ciclo familiar, quese esforça para se adaptar à situação, pois esta modal idadeterapêutica apresenta-se como um evento inesperado pelo paciente, queo remetea uma relação de dependência a uma equipeespecializada, a vários medicamentos diários e, principalmente, à dependência a uma máquina para sobreviver.

Quando uma pessoa, que sustenta a família, é acometida pela doença renal, ocasiona interferência no trabalho, tendo que se afastar dele, alguns muitas vezes sem a qualidade de segurado pela previdência social, efica a mercê, tendo que ser sustentado por familiares. A falta de recursos econômicos e os gastos com a medicação e exames que muitas vezes não são fornecidos pelo Sistema Ú nico deSaúde (SUS) levam consequentemente ao desespero e desânimo, fazendo o paciente ter vontade de abandonar o tratamento.

Cabe ao assistente social nesta perspectiva mediar, junto aos gestores de saúde, possibilidades de atender esse paciente que possui suas particularidades por ter uma doença séria e que requer constante controle.

No contexto das atribuições edos desafios que vêm sendo reiteradamente colocados ao serviço social, énotório quetenhamosquerepensar a cada dia nossas práticas profissionais para atender e dar respostas condizentes aos nossos usuários.

Devemos observar, no entanto, que construir esse pensamento do serviço social na área da saúde impõe colocá-lo no âmbito da discussão interdisciplinar, permitindo dar concretude, direcionalidade e visibilidade à profissão. Essa discussão torna-se fundamental para impulsionar a transformação das práticas profissionais na área da saúde, como afirma M erhy²: N estes muitos anos de militância e acumulação de experiências vivenciadas na busca da mudança do modo de produzir saúdeno Brasil, aprendemos que: ou esta éuma tarefa coletiva do conjunto detrabalhadores de saúde, no sentido de modificar o cotidiano do seu modo de operar o trabalho no interior dos serviços de saúde, ou enormes esforços de reformas macro-estruturais e organizacionais, nas quais temos metido, não servirão para quase nada.

Retomando a reflexão sobre as atribuições, cabe ao médico prescrever a medicação, à enfermeira, orientar sobre o tratamento, à nutricionista, informar sobre a dieta ea ingesta hídrica e ao serviço social, o papel de proporcionar informação e esclarecimento quanto ao quadro clínico do paciente, promovendo seu bem-estar, além de traduzir aos demais membros da equipe de trabalho os aspectos sociais do paciente para haver melhor condução nas intervenções profissionais, levantar o perfil do paciente com IRC, solicitar medicamentos através de processos encaminhados à Secretaria Estadual de Saúde, entrevistar e orientar pacientes em início de tratamento, viabilizar o transporte para tratamento, realizar visitas domiciliares, agendar consultas com outras especialidades, encaminhar para exames de transplante renal, organizar a transferência de pacientes para outras clinicas, controlar 0 protocolo de transplante com a equipe de enfermagem, encaminhar o paciente para acessar seus recursos sociais ou previdenciários e realizar atendimento ambulatorial e hospitalar.

Outro compromisso quetemos com o paciente é o de planejar intervenções educativas sobre higiene, alimentação e aderência ao tratamento, para que o próprio paciente também assuma os cuidados e o controle sobreo próprio tratamento.

Ao considerar a prática do assistente social junto aos pacientes renais e seu grupo familiar, é oportuno destacar os desafios encarados pelo profissional na sistematização de suas ações baseadas num referencial teórico metodológico que fortaleça o usuário no acesso e no processo de mudanças da realidade na qual se insere, capacitando-o para a ampliação dos direitos e efetivação da cidadania.

Como forma sistematizada de intervenção, 0 profissional poderá, a partir de sua concepção política, operacionalizar os el ementos que darão suporte teórico para a sua práxis, no sentido de criar possibilidades aos pacientes de compreender a relação homem/mundo, tornando-se capazes de desvelar as determinações da realidade imediata em que os problemas percebidos como síntese de múltiplos fatores precisam ser objeto de interven ção.

A assistência social no campo da saúde requer uma análise muito mais ampla da realidade social desses sujeitos desprovidos em termos socioeconômicos, a fim de que se vejam como pessoas titulares de direitos, já que a própria patologia os deprime e desmotiva pelo tratamento imposto. 
Pressupõem-se então que esses indivíduos estejam inseridos numa dinâmica contraditória, em que 0 antagonismo da classe é visivelmente presente na sociedade, deixando óbvio a igualdade perante a lei, mas também a desigualdade das relações sociais. N essa perspectiva, um dos desafios claramente percebidos no cotidiano diz respeito à falta de prioridades no que concerne aos recursos disponíveis, ou seja, 0 acesso aos benefícios assistenciais que dêem su porte ao tratamento do doente.

No que diz respeito à família, a sua participação em todo o processo do tratamento torna-se essencial, uma vez queo pacientese sentirá apoiado e seguro para dar continuidade ao tratamento. Trabal har com a família nessa perspectiva é, sobretudo, trabalhar as relações, tendo em vista reforçar os vínculos afetivos, esclarecendo todo o processo de tratamento do pacientee possíveis intercorrências, assim como promover paralelamente reflexões acerca dos aspectos sociais que envolvem a vida do paciente.

N esse sentido, ressal ta-se a necessidade do assistentesocial propiciar condições deesclarecimento e comunicação para seus usuários, compreendendo a individual idade do ser social e seus determinantes estruturais diante das relações sociais.

Tais considerações se fazem necessárias no trabalho do profissional a partir do momento que resgata os determinantes históricos presentes nas particularidades de cada paciente, que não podem ser vistas apenas em sua representação ime diata, mas convertidas em situações concretas, a partir da construção de suas determinações por uma teia de mediações suficientementecapazes de recuperar a importância do indivíduo, sem perder de vista a dimensão da totalidade.

\section{Conclusão}

Duranteo desenvolvimento desteartigo, constatamos a escassez de pesquisas que valorizem a perspectiva do indivíduo com IRC e seus famili- ares, especialmente no que se refereà questão da interven ção no serviço social nesta temática.

Através deste levantamento, pôde-se entrar em contato com as reações quea doença crônica traz para a família. Tal constatação permite concluir que o profissional assistente social se faz importante, pois auxiliará ao promover orientação e suporte para adaptação, uma vez que o adoecimento crônico acarreta situações de crise, limitações e perdas queirão influenciar na estrutura familiar. Utilizamos também al gumas narrativas de pacientes, buscando compreender 0 significado por eles atribuídos à hemodiálise e 0 impacto dessa modalidade em suas vidas.

Outra constatação éque, infelizmente, a atualidadenos mostra que muitos profissionais de saúde, ao invés de direcionarem sua atenção para a pessoa doente, focalizam a doença da pessoa, perpetuando assim o reducionismo do modelo biomédico. 0 desafio éjustamente libertar os profissionais da saúde dessa preocupação mórbida em relação aos processos do corpo e da visão técnica reducionista e desumanizante do tratamento.

Concordamos com Barbosa et al. ${ }^{3}$ quando ressaltam a necessidade dos profissionais desaúde compreenderem os pacientes em programa de hemodiálise, como um tratamento considerado inevitável, inadiável equetem consequências diretas por toda a vida do paciente, evitando assim serem agentes desencadeadores de novos conflitos e tensões.

Todas as pessoas possuem a sua história de vida. A relação entre profissionais e o individuo doente é, antes de tudo, uma relação interpessoal. Nesse contato, as histórias se cruzam, se encontram, secompletam, seconfundem. Em alguns momentos, profissional e paciente constroem juntos uma nova história, uma história viva.

0 assistente social, assim como toda equipe multidisciplinar, deve estar atento às necessidades da família, pois o adoecer possui para cada membro um significado que deve ser levado em consideração e o impacto da doença crônica é sentido por todos. 


\section{Referências}

1. Lima AMC, M endonça Filho JB, Diniz JSS. Insuficiência renal crônica - a trajetória de uma prática. In: Romano BW, organizador. A prática da psicologia nos hospitais. São Paulo: Pioneira Thomson Learning; 1995. p. 77-92.

2. M erhy EE. Em busca do tempo perdido: a micropolítica do trabalho vivo em saúde. São Paulo: Hucitec; 1997.

3. Barbosa JC, Aguillar OM, Boemer MR. O significado de viver com a insuficiência renal crônica. Revista Brasileira de Enfermagem 1999; 52(2):293-302.

Artigo apresentado em 27/01/2008

Aprovado em 17/02/2009

Versão final apresentada em 02/03/2009 